\title{
Effects of gamma irradiation and comparison of different extraction methods on sesquiterpene lactone yields from the medicinal plant Thapsia garganica L. (Apiaceae)
}

Mohamed Ibrahim, Abir M.; Martinez-Swatson, Karen A.; Benkaci-Ali, Farid; Cozzi, Federico; Zoulikha, Ferhat; Simonsen, Henrik Toft

Published in:

Journal of Applied Research on Medicinal and Aromatic Plants

Link to article, DOI:

10.1016/j.jarmap.2017.09.002

Publication date:

2018

Document Version

Peer reviewed version

Link back to DTU Orbit

Citation $(A P A)$ :

Mohamed Ibrahim, A. M., Martinez-Swatson, K. A., Benkaci-Ali, F., Cozzi, F., Zoulikha, F., \& Simonsen, H. T. (2018). Effects of gamma irradiation and comparison of different extraction methods on sesquiterpene lactone yields from the medicinal plant Thapsia garganica L. (Apiaceae). Journal of Applied Research on Medicinal and Aromatic Plants, 8, 26-32. https://doi.org/10.1016/j.jarmap.2017.09.002

\section{General rights}

Copyright and moral rights for the publications made accessible in the public portal are retained by the authors and/or other copyright owners and it is a condition of accessing publications that users recognise and abide by the legal requirements associated with these rights.

- Users may download and print one copy of any publication from the public portal for the purpose of private study or research.

- You may not further distribute the material or use it for any profit-making activity or commercial gain

- You may freely distribute the URL identifying the publication in the public portal 
1 Effects of gamma irradiation and comparison of different extraction methods on 2 sesquiterpene lactone yields from the medicinal plant Thapsia garganica L. (Apiaceae)

3

4

5

6 7

\section{Abir Mohamed Mohamed Ibrahim ${ }^{\text {a, }, \text {, Karen Agatha Martinez-Swatson }}{ }^{\text {b, e, }}$, Farid} Benkaci-Alic, Federico Cozzi ${ }^{d}$, Ferhat Zoulikha ${ }^{\text {a }}$, Henrik Toft Simonsen ${ }^{\mathrm{e}, ~ *}$

${ }^{\text {a }}$ Department of Food Technology, Laboratory of Food Technology and Humane nutrition , National School Agronomic (ENSA) Avenue Hassan Badi,16000, El-Harrach, Algiers, Algeria.

${ }^{\mathrm{b}}$ National History Museum of Denmark, University of Copenhagen, Øster Voldgade 5-7, 1350 Copenhagen, Denmark.

${ }^{\mathrm{c}}$ Laboratory of Organic and Functional Analysis, Faculty of Chemistry, University of Sciences and Technologies Houari Boumediène, USTHB, BP 32 El Alia, Bâb-Ezzouar, Algiers, Algeria.

d Department of Plant Biology and Environmental Sciences, University of Copenhagen, Thorvaldsensvej 40, 1871 Frederiksberg, Denmark.

e Department of Biotechnology and Biomedicine, Technical University of Denmark, Søltofts Plads, 2800 Kgs. Lyngby, Denmark.

*Correspondance E-mail: hets@dtu.dk

${ }^{1}$ Authors contributed equally this work 
24 Abstract

\section{Ethnopharmacological relevance}

Thapsia garganica L. roots are used in Algerian traditional medicine for a number of ailments.

It is used in a poultice as an antitussive treatment of acute bronchitis and pneumonia, in preparations with milk or oil taken orally to treat common lung diseases, and with the direct application of root sections for the soothing of dental pains.

30

\section{Aim of the study}

The objective of this study was to evaluate the combined effect of microwave assisted extraction and gamma irradiation on sesquiterpene lactones in T. garganica extracts

\section{Materials and methods}

To evaluate the combined effect of microwave assisted extraction and gamma irradiation on the highly bioactive compounds found in extracts of Algerian T. garganica, samples from different locations in Algeria were prepared by extraction from dried leaf and root samples of dried plant material, using different extraction methods. Quantification of the compounds of interest was done using an HPLC. The antioxidant activity extracts was determined using the two free radical scavenging assays: the 2,2-diphenyl-picryl-hydrazyl (DPPH) and the 2,2'azino-bis(3-ethylbenzothiazoline-6-sulphonic acid) diammonium salt (ABTS).

\section{Results}

It was found that location and extraction method had significant impact on the phytochemical composition of extracts. Gamma irradiation was found to have no effect on the phytochemical composition of the plant extracts or on their antioxidant properties.

\section{Conclusion}

The study has shown that microwave assisted extraction is an effective method for investigating chemical compounds in T. garganica and the results support the notion that gamma irradiation for sterilization do not alter the chemical composition.

\section{The authors wish to clarify that we cannot recommend the usage of any parts of $T$.} garganica, in any form, for any remedy due to its very high toxicity.

Keywords: Thapsia garganica; gamma irradiation; microwave assisted extraction; thapsigargin; antioxidant 


\subsection{Traditional use in Algeria}

Thapsia garganica L. (Apiaceae) is a medicinal plant commonly found in Algeria, along the coast, in the plains, in the Saharan Atlas Mountains and in the north of the Saharan desert (Hammiche et al., 2013). It is commonly referred to as: Toufelt in Berber; adhriss by the Kabyle people in the North; thapsie, bounafaa or bou-nafit «that of efficacy» in Arabic; faux fenouil (false fennel) and Thapsia du mont Gargan in French(Hammiche et al., 2013). In English, it is known as the deadly carrot. All parts of the plant are known to be toxic and irritant to the skin, causing blisters, erythema and itching, and the resin of the roots has been found to be particularly toxic (Andersen et al., 2015b). Due to this toxicity T. garganica is not allowed in any official pharmaceutical preparation, and we cannot recommend the usage of T. garganica roots or fruits, in any form, for any remedy due to its very high toxicity. $T$. garganica roots are however used in Algerian traditional medicine for a number of ailments. In Kabylia, the Kabyle people use the root to make a "depurative cure" at the onset of spring (Hammiche et al., 2013). They also use the roots to make a poultice, which is applied to the chest as an antitussive treatment of acute bronchitis and pneumonia. Great care is taken in the preparation and its use is limited; in fact, it is a treatment of last resort when bad weather prevents travel (Hammiche, 2015). If the medical condition is less severe, the oil in which a fresh root is cooked is either rubbed on the chest for its "purgative" properties or ingested in small quantities (Hammiche, 2015). Other traditional uses in Algeria include a preparation with milk or oil taken orally to treat common lung diseases, and the soothing of dental pains with the direct application of root sections (Hammiche et al., 2013).

The toxicity of $T$. garganica originates from the presence of thapsigargin (Fig. 1) and other sesquiterpene lactones (Andersen et al., 2015a; Andersen et al., 2017; Drew et al., 2009; Simonsen et al., 2013). Thapsigargin makes up $0.2-1.2 \%$ of the dry weight of the plant's roots (Andersen et al., 2015b). The pharmacological activity of thapsigargin is due to its inhibition 83 of the sarco-endoplasmic reticulum $\mathrm{Ca}^{2+}$-ATPase (SERCA) in mammalian cells, which leads to cell apoptosis (Simonsen et al., 2013).

\subsection{Antioxidant activity}

Both the food and pharmaceutical industries have shown a continuing interest in finding naturally occurring antioxidants for use in the preservation of foods or medicinal products, in 
and harmful effects on the environment (Prakash et al., 2015). Essential oils from aromatic and medicinal plants, in particular, have been of special interest due to their strong antioxidant activity and antimicrobial constituents in their tissues (Di Venere et al., 2016; Golubović et al., 2014). It has previously been seen that certain Algerian medicinal plants, including $T$. garganica, contain strong radical scavengers and can therefore be useful as sources of natural antioxidants for both medicinal and commercial use (Djeridane et al., 2006). However, as many of these plants contain toxic compounds, toxicity issues need to be addressed to ensure the antioxidants are safe to use.

\subsection{Irradiation of medicinal herbs}

Medicinal plants are widely used in Algerian folk medicine, especially by the elderly and rural communities with limited access to doctors. However, the plants are subject to deterioration from chemical and microbial processes that occur before reaching the end-user during harvesting, processing, distribution and storage. These processes can alter their efficacy and in some cases their safety, so there is a demand for methods of decontamination and preservation in order to improve consumer safety and therapeutic efficacy. Food irradiation is commonly used to sterilise and to reduce food losses due to spoilage, and it has replaced once commonly used chemical fumigants, like ethylene oxide, and other chemical preservatives that have been reported to be hazardous to human health (Seo et al., 2007). The use of gamma irradiation on food products is approved by the Food and Agriculture Organisation (FAO), the International Atomic Energy Agency (IAEA) and the World Health Organisation (WHO)(Joint, 2009). It has been shown to be a safe, environmentally friendly and energy efficient method to sterilise plant products. It is also a well-established industrial process for the sterilisation of medicinal plants in a number of facilities worldwide and in general do not affect the chemical composition of the leaves and roots (Garg and Gupta, 2016; Seo et al., 2007).

\subsection{Extraction methods}

Traditional extraction methods of medicinal plants include decoction or maceration in an organic solvent. These methods however, are highly energy dependent and time consuming. Microwave assisted extraction (MAE) has been found to be a reliable alternative as it requires a lower energy input to result in the same or even higher extraction yields, reduces the use organic solvents, shortens extraction times and improves the reproducibility of results. This extraction method has been used for the analysis of bioactive compounds in a number of medicinal plants (Akloul et al., 2014; Benkaci-Ali et al., 2006; Kennouche et al., 2015). 
123 However, care should be taken to choose suitable conditions to avoid the thermal degradation

124 of the analytes of interest. Sample preparation and extraction methods are important to 125 consider when studying medicinal plants, as the methods chosen depend on the target compounds and can affect the phytochemical composition of the final extracts.

128 Here we investigate the chemical composition of extracts of T. garganica from different 129 regions in Algeria. We evaluate the combined effects of microwave assisted extraction and 130 gamma irradiation on the extraction yield of the bioactive compounds as well as on the 131 antioxidant activity of the extract.

\section{Materials and Methods}

\section{2.1. Plant material}

135 Thapsia garganica L. (Apiaceae) roots and leaves were collected between March and April 136 in 2014 and 2015 during flowering, from two locations in Algeria: Médea (Aïn Boucif) (GPS 137 coordinates $\mathrm{N} 35^{\circ} 53^{\prime} 28^{\prime \prime} / \mathrm{E}^{\circ} 9^{\prime}$ 31") and Béjaia (Kherrata) (GPS coordinates N36 29' $\left.13834 " / E 5^{\circ} 16^{\prime} 39^{\prime \prime}\right)$. At each site 50 individuals were sampled. For each individual representative 139 leaf material was taken across the entire plant and roots were dug out. Herbarium vouchers 140 were made for one individual per site. The herbarium vouchers are deposited at the Natural 141 History Museum of Denmark, Herbarium C (C10011584, C10011585; leg. Abir Mohamed 142 Mohamed Ibrahim). The local name, the used plant parts, methods of preparation and 143 administration, and medicinal uses were collected from local inhabitants. Samples were 144 identified Dr. Abdelkrim of the Botanical department at the National School Agronomic, 145 Algiers, Algeria, air-dried and stored at room temperature in the laboratory of chemistry. The 146 collections were made according to Algerian regulations.

\section{$147 \quad$ 2.2. DNA extraction, amplification and sequencing}

148 The taxonomy and species concept of Thapsia is not resolved (Weitzel et al., 2014), thus to 149 confirm the identity of the collected samples, total genomic DNA from one sample per site 150 (herbarium accession numbers: C10011584, C10011585) was extracted from $15 \mathrm{mg}$ of dried 151 leaf fragments, using the QiagenDNeasy Kit (Qiagen, Copenhagen, Denmark) following the 152 manufacturer's protocol. The nuclear ribosomal internal transcribed spacer (nrITS) region was 153 sequenced as described previously (Weitzel et al., 2014), using primers ITS4 and ITS5. 154 Sequences were edited and assembled using CLC Main Workbench 7 software. BLAST 155 analysis confirmed material from both sites to be T. garganica ( $99 \%$ match) as previously 
156 identified (Weitzel et al., 2014). The new sequences generated are deposited in GenBank, with

157 the following accession numbers: (submitted to GenBank).

\subsection{Irradiation}

$200 \mathrm{~g}$ of dried root and leaf samples were subjected to the following doses (D) of gamma radiation (values in KGy): $\mathrm{D}_{1}: 0.1, \mathrm{D}_{2}: 0.3, \mathrm{D}_{3}: 0.7, \mathrm{D}_{4}: 1, \mathrm{D}_{5}: 3, \mathrm{D}_{6}: 7$ and $\mathrm{D}_{7}: 10$; at room temperature in the Centre of Nuclear Research Algiers, Algeria (Centre de Recherche Nucléaire d'Alger, CRNA) with a ${ }^{60} \mathrm{Co}$ source. Non-irradiated ( $\left.\mathrm{D}_{0}: 0 \mathrm{kGy}\right)$ samples were used as negative controls. The irradiated samples were kept in the dark and at room temperature (ca $22^{\circ} \mathrm{C}$ ) until analysis.

\subsection{Extraction and fractionation of plant material of T. garganica for HPLC quantification}

The individual samples of leaves and roots collected at each site were pooled to make a representative sample of leaves and roots for each area.

170 Simple extraction (SE): $1.5 \mathrm{~mL}$ of organic solvent (1:1 mixture of $80 \% \mathrm{MeOH}$ in water and $80 \%$ Acetone in water) was added to $50 \mathrm{mg}$ of homogenised dried and ground plant material using liquid nitrogen $\left(-196^{\circ} \mathrm{C}\right)$ to preserve the samples, then vortexed thoroughly and agitated overnight in a thermomixer (Eppendorf ${ }^{\circledR}$ Thermomixer Compact) at $850 \mathrm{rpm}$ at $25{ }^{\circ} \mathrm{C}$. Samples were then centrifuged for $10 \mathrm{~min}$ at $10,000 \mathrm{rpm} .1 \mathrm{~mL}$ of the supernatant was evaporated to total dryness in a vacuum concentrator (Scan Speed Maxi Vac Evaporator). 250 $\mu \mathrm{L}$ of $80 \%$ methanol was then added to re-suspend the extract for HPLC analysis.

Classical maceration (CM): $40 \mathrm{~g}$ samples of dried and ground roots and leaves (irradiated and untreated) of T. garganica were submerged in $100 \mathrm{~mL}$ of methanol at $40{ }^{\circ} \mathrm{C}$ for $10 \mathrm{~h}$ under magnetic stirring. After filtration, the methanol extracts were concentrated under reduced pressure to obtain crude extracts and then lyophilized to eliminate all trace of solvent and stored at $4{ }^{\circ} \mathrm{C}$. Before HPLC analysis, $1 \mathrm{mg}$ of each sample was re-suspended in $1 \mathrm{~mL} 100 \%$ methanol.

183 Microwave assisted extraction (MAE): $40 \mathrm{~g}$ of each dried sample (irradiated and untreated) were ground to powder. Samples were then extracted in $100 \mathrm{~mL}$ methanol in a microwave device as previously described (Akloul et al., 2014) for $30 \mathrm{~min}$. The resultant mixture was filtered under vacuum and the filtrate was evaporated to near dryness. The samples were then completely lyophilized and stored at $4{ }^{\circ} \mathrm{C} .1 \mathrm{mg}$ of each dry extract was re-suspended in $1 \mathrm{~mL}$ $100 \%$ methanol before HPLC analysis. 


\subsection{Chemical Standards}

191 Standards extracted from the fruits of $T$. garganica were used as references for the identification and quantification of thapsigargin $(\mathrm{Tg})$, nortrilobolide $(\mathrm{Nb})$ and thapsigargicin (Tc) (donated by Søren Brøgger Christensen, University of Copenhagen, Denmark). Standard solutions were prepared in triplicate, diluted in 80\% methanol (standard dilutions: 5, 25, 50, $200,400,500,600,800,1000 \mu \mathrm{g} / \mathrm{mL})$.

\subsection{HPLC analysis}

198 All samples were filtered in centrifugal filters (Ultrafree $\mathbb{B}$ MC GV, $0.22 \mu \mathrm{m}$ Durapore $\mathbb{}$ 199 PVDF) just before injection into the HPLC. HPLC analysis was performed on an Analytical 200 HPLC-UV Shimadzu Prominence (column oven $30{ }^{\circ} \mathrm{C}$, autosampler $15^{\circ} \mathrm{C}$ ) and performed on 201 a Kinetix EVO C18 100A column $(5 \mu \mathrm{m}, 50 \mathrm{~mm} \times 3 \mathrm{~mm}$; Phenomenex). Acetonitrile (solution 202 A) and milliQ water (solution B) were used as the mobile phase with a flow rate of 0.5 $203 \mathrm{~mL} / \mathrm{min}$. The gradient program was as follows: 50\% A (0-1 min, linear gradient), 100\% A 204 (6-9 min, linear gradient), 5\% A (14-16 min, linear gradient), 50\% A (17-23 min, linear 205 gradient) the flow rate was fixed at $0.5 \mathrm{~mL} / \mathrm{min}$. Eluting compounds were detected with UV 206 at $230 \mathrm{~nm}$. Each sample was prepared in triplicate and $10 \mu 1$ was injected into the HPLC.

207 Calibration curves were generated based on triplicate analysis. To obtain a standard curve for 208 quantification, the calibration graphs were linear in the concentration range $5-1000 \mu \mathrm{g} / \mathrm{mL}$.

209 The calibration curves for each standard had a correlation coefficient of 0.999.

210

\section{2.7. Antioxidant activity}

212 The antioxidant potential of T. garganica root and leaf extracts was determined using the two 213 most widely used free radical scavenging assays: the 2,2-diphenyl-picryl-hydrazyl (DPPH) 214 and the 2,2'-azino-bis(3-ethylbenzothiazoline-6-sulphonic acid) diammonium salt (ABTS).

215 All experiments were performed in triplicate for the different concentrations of each plant 216 extract.

217 DPPH assay: The free radical scavenging capability of each extract solution was measured 218 from the bleaching of a purple solution of DPPH as described previously (Şahin et al., 2004). $2191 \mathrm{~mL}$ of methanol solution of $60 \mu \mathrm{M}$ DPPH was mixed with $26 \mu \mathrm{L}$ of each of the methanolic 220 extracts of the roots and leaves at different concentrations, $100-1000 \mathrm{mg} / \mathrm{mL}$ and $25-200$ $221 \mathrm{mg} / \mathrm{mL}$ respectively. The reaction mixture was carried out in capped glass test tubes. After $22230 \mathrm{~min}$ of incubation at room temperature, the absorbance was measured at $517 \mathrm{~nm}$ using an 
optizen Mecasys spectrophotometer. The inhibition percentage of DPPH free radicals (I\%) was calculated as follows:

$$
\mathrm{I} \%=\left(\mathrm{A}_{0}-\mathrm{As}_{\mathrm{S}} / \mathrm{A}_{0}\right) \times 100
$$

The $\mathrm{DPPH}^{*}$ stock solution was freshly prepared before each reaction to reduce the loss of free radical activity during the experiment.

ABTS assay: The ABTS method followed (Scalzo et al., 2005) and is based on the capacity of the test samples to scavenge the coloured ABTS radical cation (green $\mathrm{ABTS}^{\cdot+}$ ), obtained by oxidation with potassium persulphate solution for $12-16 \mathrm{~h}$ at $4{ }^{\circ} \mathrm{C}$ away from light. The absorption peak of $\mathrm{ABTS}^{-+}$is at $734 \mathrm{~nm}$ and the addition of antioxidants reduces it to its colourless form. On the day of the assay, the ABTS •+ solution was diluted with ethanol until absorbance of $1.00 \pm 0.02$ at $734 \mathrm{~nm} .25 \mu \mathrm{L}$ of sample extracts were added to $1 \mathrm{~mL}$ of the $\mathrm{ABTS}^{\cdot+}$ solution. The decrease in absorbance was measured after 7 min of incubation at 734 nm. Ethanol was used to set the zero. The radical scavenging activity of the samples tested, expressed as a percentage of the inhibition of $\operatorname{ABTS}^{\circ+}(\mathrm{I} \%)$, were calculated using the formula:

$$
\mathrm{I} \%=\left[\left(\mathrm{A}_{0}-\mathrm{As}_{\mathrm{S}}\right) / \mathrm{A}_{0}\right] \times 100
$$

For both assays, a linear regression was determined and used to calculate the $\mathrm{IC}_{50}$ value. Low $\mathrm{IC}_{50}$ values indicate greater antioxidant activity.

\section{Results and Discussion}

All results presented are averages $( \pm \mathrm{SD})$ of three repetitions. The treatments were compared by performing a Two-Way factorial ANOVA (Analysis of Variance) on the phytochemical composition of the extracts and a Two-Way ANOVA on the antioxidant activities measured. This was followed by the post-hoc Tukey HSD (honest significant difference) test (95\% confidence level) to compare the effect of different conditions on the parameters measured. Values of $\mathrm{p}<0.05$ were accepted as significant. The ANOVA analyses were performed in R, Tukey HSD with the R package agricolae (De Mendiburu, 2014) and the graphs were made using the R package ggplot2 (Wickham, 2009).

\subsection{Effect of the gamma irradiation and extraction technique on the phytochemical} composition in thapsigargins

The results show that across all the three extraction methods, gamma irradiation had no significant effect on the phytochemical composition of the extracts obtained from $T$. garganica (Figure 2A, Table 1, Table 2). Thapsigargin is today isolated from plant grown in Ibiza (Spain) and shipped around the world for extraction. We can suggest that in the future 
256 the plant material can be safely sterilised by gamma irradiation and thereby add to the 257 conservation of the product during transport.

258 Figure 2B illustrates the effect of the extraction methods on the chemical extracts, which was found to be significantly different from each other in both root extracts (F-value=7.21, Pvalue $=0.001)$ and leaves extracts $(\mathrm{F}-\mathrm{value}=4.47, \mathrm{P}$-value $=0.01)$ (Table 2). Simple extraction with liquid nitrogen (SE) of dried T. garganica roots and leaves proved to be the least effective method to extract bioactive compounds from small amounts of plant material, with no significant difference between microwave assisted extraction (MAE) and classical maceration (CM). MAE however presents the advantage of being rapid and reproducible as well as requiring less energy than conventional methods like CM (Azwanida, 2015). MAE is known to cause the thermal degradation of certain analytes, but in here, it has been shown to be a suitable method for the extraction of thapsigargins as previously suggested (Benkaci-Ali et al., 2006). The only chemical variations observed between the different extracts were that the $\mathrm{Tg}$ content in both the leaves and the roots was higher than $\mathrm{Tc}$ and $\mathrm{Nt}$; dried roots of $T$. garganica have significantly higher levels of $\mathrm{Tg}$ than in the dried leaves $(\mathrm{P}<0.00$, Figure $2 \mathrm{~B})$. $\mathrm{Nt}$ was the least abundant compound in all the samples. This has already been reported (Smitt et al., 1995), but new localities have been investigated in this study. Clear differences were also seen between the two study regions for the roots only, with the root extracts from the Béjaia region consistently having larger quantities of the three compounds studied (Figure 2B). Locality has previously been shown to have an effect on the phytochemical composition of T. garganica roots (Drew et al., 2012; Smitt et al., 1995), but the cause(s) of these variations have not yet been identified. We hypothesise that there are biological and environmental factors responsible for these fluctuations. Further investigations are needed to determine the best time to harvest $T$. garganica to optimise Tg extraction, considering that the compound remains extremely expensive at $€ 187$ per mg (Sigma-Aldrich).

\subsection{Effect of gamma irradiation on the antioxidant properties of T. garganica}

Gamma irradiation was found to have no significant effect on the antioxidant activity of $T$. garganica root extracts (Table 3). However, there was significant difference between the scavenging activities of both leaf and root extracts between the Médéa and Béjaia regions, for both the $\mathrm{ABTS}^{\bullet}$, leaves $(\mathrm{F}$-value $=4.97, \mathrm{P}$-value $=0,05)$, roots $(\mathrm{F}$-value $=8.68, \mathrm{P}$-value $=$ $0.01)$ and DPPH assays, leaves $(\mathrm{F}$-value $=9.66, \mathrm{P}$-value $=0.01)$, roots $(\mathrm{F}$-value $=59.77, \mathrm{P}$ value $=0.00$ ). It was noted that $\mathrm{IC}_{50}$ values for the $\mathrm{DPPH}$ assay were higher than those 
that DPPH assays are a rapid and reliable test for the antioxidant capacity of plant extracts,

291 but also an advantageous assay applicable to both hydrophilic and lipophilic environments.

292 The leaf extracts had a much higher scavenging activity than the root extracts with those from 293 the Béjaia region generally higher than the extracts from Médéa. This again shows that there

294 are biological or environmental factors responsible for these fluctuations. As T. garganica and

295 other Algerian medicinal plants have been proposed as potential sources of natural 296 antioxidants (Djeridane et al., 2006). This shows that whilst gamma irradiation can be used as

297 a sterilisation method, the locality where a plant is collected can affect its antioxidant 298 potential.

300 4. Conclusion

301 A difference in the chemical composition of Thapsigargins was observed between different

302 tissues of T. garganica. The highest amount of Thapsigargin was found to be in the roots of 303 samples collected in Béjaia. There was a significant effect of locality on the phytochemical 304 composition of the roots but not in the leaves. Locality also affected the antioxidant properties 305 of both the leaf and root extracts.

306 Of the extraction methods used, MAE and CM were equally effective and more efficient than

307 SE to extract bioactive compounds from small amounts of plant material. Gamma irradiation

308 had no significant effect on the phytochemical composition of T. garganica as well as the 309 antioxidant activity of the extracts.

\section{5. Author contributions}

312 A. Mohamed Mohamed Ibrahim and K. A. Martinez-Swatson established the major part of 313 the results and contributed equally to the manuscript. A. Mohamed Mohamed Ibrahim

314 conducted fieldwork for collects of samples and extraction, prepared samples for HPLC 315 analysis, conducted the antioxidant activity test. K. A. Martinez purified the chemical 316 compounds used as standards and ran the HPLC analysis. F. Cozzi directed and supported the 317 HPLC analysis. F. Benkaci-Ali conceived the project and contributed to the manuscript. F. 318 Zoulikha supervised the writing. H. T. Simonsen initiated, directed and supported the research 319 and writing of the manuscript. All authors edited and approved the final manuscript. 320

\section{Acknowledgments}


322 This work was supported by Department of Food Technology, Laboratory of Food 323 Technology and Humane nutrition, National School Agronomic (ENSA) (AMMI, FB-A) and 324 by MEDPLANT, a Marie Curie Actions Initial Network grant \#606895 (KAM). We would 325 like to thank Centre of Nuclear Research Algiers, (CNRA) for providing the Gamma Ray 326 irradiation. The Standards were extracted and purified under the direction of Søren Brøgger 327 Christensen and Huizhen Liu at the Department of Drug Design and Pharmacology, 328 University of Copenhagen, Denmark.

329

330

331 
332

333

334

335

336

337

338

339

340

341

342

343

344

345

346

347

348

349

350

351

352

353

354

355

356

357

358

359

360

361

362

\section{References}

Akloul R, Benkaci-Ali F, Eppe G, 2014. Kinetic study of volatile oil of Curcuma longa L. rhizome and Carum carvi L. fruits extracted by microwave-assisted techniques using the cryogrinding. Journal of Essential Oil Research 26(6), 473-485.

Andersen TB, Cozzi F, Simonsen HT, 2015a. Optimization of biochemical screening methods for volatile and unstable sesquiterpenoids using HS-SPME-GC-MS. Chromatography 2(2), 277-292.

Andersen TB, Lopez CQ, Manczak T, Martinez KA, Simonsen HT, 2015b. Thapsigargin from Thapsia L. to Mipsagargin. Molecules 20(4), 6113-6127.

Andersen TB, Martinez KA, Rasmussen SA, Boughton BA, Jørgensen K, Andersen-Ranberg J, Nyberg N, Christensen SB, Simonsen HT, 2017. Localization and in-vivo characterization of Thapsia garganica CYP76AE2 indicates a role in thapsigargin biosynthesis. Plant Physiology 174(1), 56-72.

Azwanida NN, 2015. A review on the extraction methods use in medicinal plants, principle, strength and limitation. Medicinal Aromatics Plants 4(196), 2167-0412.

Benkaci-Ali F, Baaliouamer A, Meklati BY, 2006. Kinetic study of microwave extraction of essential oil of Nigella sativa L. seeds. Chromatographia 64(3-4), 227-231.

De Mendiburu F, 2014. Agricolae: statistical procedures for agricultural research. $<$ https://CRAN.R-project.org/package=agricolae $>$ (accessed Octpber.2016).

Di Venere D, Gatto MA, Ippolito A, Bianco VV, 2016. Antimicrobial potential of wild edible herbaceous species, Mediterranean Wild Edible Plants. Springer, pp. 233-252.

Djeridane A, Yousfi M, Nadjemi B, Boutassouna D, Stocker P, Vidal N, 2006. Antioxidant activity of some Algerian medicinal plants extracts containing phenolic compounds. Food Chemistry 97(4), 654-660.

Drew DP, Krichau N, Reichwald K, Simonsen HT, 2009. Guaianolides in Apiaceae: Perspectives on pharmacology and biosynthesis. Phytochemistry Reviews 8(3), 581-599.

Drew DP, Rasmussen SK, Avato P, Simonsen HT, 2012. A comparison of headspace solidphase microextraction and classic hydrodistillation for the identification of volatile constituents from Thapsia spp. provides insights into guaianolide biosynthesis in Apiaceae. Phytochemical Analysis 23(1), 44-51.

Garg N, Gupta PC, 2016. Irradiation: A Technique for Microbial Decontamination of Medicinal Plants, Microbes in Food and Health. Springer, pp. 225-237. 
364 Golubović T, Palić R, Kitić D, Stojanović G, Zlatković B, Ristić M, Pavlović D, 2014.

365 Composition, antioxidant and antimicrobial activities of methanol extracts of some Acinos

366 Miller species. Natural Product Communications 9(5), 731-735.

367 Hammiche V, 2015. Traitement de la toux à travers la pharmacopée traditionnelle kabyle.

368 Phytothérapie 13(6), 358-372.

369 Hammiche V, Merad R, Azzouz M, 2013. Plantes toxiques à usage médicinal du pourtour 370 méditerranéen. Springer, Paris.

371 Joint FAO, 2009. Irradiation to ensure the safety and quality of prepared meals. Results of the 372 coordinated research project (2002-2006). International Atomic Energy Agency, Vienna, pp. $373 \quad 1-375$.

374 Kennouche A, Benkaci-Ali F, Scholl G, Eppe G, 2015. Chemical composition and 375 antimicrobial activity of the essential oil of Eugenia caryophyllata cloves extracted by 376 conventional and microwave techniques. Journal of Biologically Active Products from Nature $3775(1), 1-11$.

378 Prakash B, Kedia A, Mishra PK, Dubey NK, 2015. Plant essential oils as food preservatives 379 to control moulds, mycotoxin contamination and oxidative deterioration of agri-food 380 commodities-Potentials and challenges. Food Control 47, 381-391.

381 Şahin F, Güllüce M, Daferera D, Sökmen A, Sökmen M, Polissiou M, Agar G, Özer H, 2004.

382 Biological activities of the essential oils and methanol extract of Origanum vulgare ssp. 383 vulgare in the Eastern Anatolia region of Turkey. Food Control 15(7), 549-557.

384 Scalzo J, Politi A, Pellegrini N, Mezzetti B, Battino M, 2005. Plant genotype affects total 385 antioxidant capacity and phenolic contents in fruit. Nutrition 21(2), 207-213.

386 Seo H-Y, Kim J-H, Song H-P, Kim D-H, Byun M-W, Kwon J-H, Kim K-S, 2007. Effects of 387 gamma irradiation on the yields of volatile extracts of Angelica gigas Nakai. Radiation 388 Physics and Chemistry 76(11), 1869-1874.

389 Simonsen HT, Weitzel C, Christensen SB, 2013. Guaianolide sesquiterpenoids - Their 390 pharmacology and biosynthesis, in: Ramawat KG, Merillon JM (Eds.), Handbook of Natural 391 Products - Phytochemistry, Botany and Metabolism of Alkaloids, Phenolics and Terpenes. 392 Springer-Verlag, Berlin, Germany, pp. 3069-3098.

393 Smitt UW, Jäger AK, Adsersen A, Gudiksen L, 1995. Comparative studies in phytochemistry 394 and fruit anatomy of Thapsia garganica and T. transtagana, Apiaceae (Umbelliferae). 395 Botanical Journal of the Linnean Society 117(4), 281-292. 
396 Weitzel C, Rønsted N, Spalik K, Simonsen HT, 2014. Resurrecting deadly carrots: towards a 397 revision of Thapsia (Apiaceae) based on phylogenetic analysis of nrITS sequences and 398 chemical profiles. Botanical Journal of the Linnean Society 174(4), 620-636.

399 Wickham H, 2009. ggplot2: elegant graphics for data analysis. Springer, New York.

400

401 


\section{Table legends}

Table 1: Comparison of the different extraction methods and gamma irradiation doses on the samples from the two study areas Médéa and Béjaia. Values are the mean of three replicates \pm standard deviation (SD) and are expressed as the percentage of compound in the dry weight of the sample $(\mathrm{DW} \%), \mathrm{P}<0.05 . \mathrm{Tg}=$ Thapsigargin, $\mathrm{Tc}=$ Thapsigargicin, $\mathrm{Nt}=$ Nortrilobolide, $\mathrm{CM}=$ Classical maceration, $\mathrm{MAE}=$ Microwave assisted extraction, $\mathrm{SE}=$ Simple extraction with liquid nitrogen, $\mathrm{MR}=$ Médéa roots, $\mathrm{ML}=$ Médéa leaves, $\mathrm{BR}=$ Béjaia roots, $\mathrm{BL}=$ Béjaia leaves. Gamma irradiation doses are given in KGy, significance $\mathrm{P}<0.05$ is compared to the control $0 \mathrm{KGy}$. Superscript letters within the same row indicate significant $(\mathrm{P}<0.05)$ differences in the compound yields between the extraction methods.

Table 2: Factorial two-way analysis of variance on the effect of $\gamma$-irradiation (gamma irradiation), extraction method and locality on the chemical variation of the extracts from $T$. garganica with significance displayed as $* * * \mathrm{P}>0.00, * * \mathrm{P}>0.001, * \mathrm{P}>0.01 . \mathrm{df}=$ degrees of freedom, Sum sq = sum of squares, Mean sq = mean square, $F_{S}=$ F statistic.

Table 3: The effect of gamma irradiation on the antioxidant activity of samples obtained by $\mathrm{CM}$ with methanol. Values are represented as the mean $\mathrm{IC}_{50}(\mathrm{mg} / \mathrm{L})$ value of three replicates \pm standard deviation at 5\% significance level. DPPH = 2,2-diphenyl-picryl-hydrazyl assay, ABTS $=$ 2,2'-azino-bis(3-ethylbenzothiazoline-6-sulphonic acid) diammonium salt assay. Gamma irradiation dosages (D) are given in $\mathrm{KGy}$. MR = Médéa roots, $\mathrm{ML}=$ Médéa leaves, $\mathrm{BR}=$ Béjaia roots, $\mathrm{BL}=$ Béjaia leaves. 


\section{Figure legends}

Figure 1: Illustration of structures of the three main sesquiterpene lactones in Thapsia garganica L. Thapsigargin (Tg), thapsigargicin (Tc), and nortrilobolide (Nt).

Figure 2: A - Stacked bar chart showing the effect of gamma irradiation on Thapsigargin (Tg), thapsigargicin (Tc) and nortrilobolide (Nt) levels in the different extracts obtained by the different extraction methods. The dose of irradiation used is shown in kGy with the control $(\mathrm{NT}=$ no treatment $)$ and each dosage extraction is represented in a different colors. The amounts presented are relative to the individual samples run. For each irradiation dosage, the extraction methods are represented with shading with the lightest shading being classical maceration (CM), the middle shading is microwave assisted extraction (MAE) and the darkest shading is simple extraction (SE). The size of the bars indicates the percentage of extraction yield, each treatment is responsible for, relative to each compound.

B - Bar plots to show the effect of the extractions methods used on the extraction yield of thapsigargin (Tg), thapsigargicin (Tc), and nortrilobolide (Nt) on samples from the two locations. $\mathrm{MR}=$ Médéa roots, $\mathrm{ML}=$ Médéa leaves, $\mathrm{BR}=$ Béjaia roots, $\mathrm{BL}=$ Béjaia leaves.

In both charts, the amount of the compounds was calculated as the percentage of the compound in the dry weight of the plant material (extraction yield). 